\section{IOS closures}

SIR - In a news item on the possible closure of Institute of Oceanographic Science laboratories (Nature 10 November, p.102), Philip Campbell belittles the status of Bidston Observatory by describing its work as being "in more applied areas such as tidal computations". In a brief telephone conversation with Dr Campbell I may have cited the group which computes most of this country's (and Australia's) tide tables as one which is especially vulnerable to a move to Surrey, but it should not be taken to typify our work. Our research group on the tides of the ocean may be said to lead the world in this area of pure geophysics, while our solid-Earth-tide study group is the only one in Great Britain. We have well known expertise in numerical modelling of the tidal and wind-driven motions of the shallow seas surrounding this country, now being extended to include the nearby shelf-edge and deep ocean. Other researchers pursue advanced studies of such dynamic features as oceanic fronts, topographical waves and mean sea level. These activities are backed up by a strong in-house instrumentation team which specializes in seagoing monitoring techniques and tidal measuring equipment from the sea-shore to $5 \mathrm{~km}$ deep in the ocean. Last but not least, Bidston houses the data banking facility of the UK Marine Information and Advisory Service, an excellent marine library, and a local meteorological service.

\section{D.E. CARTWRIGHT}

Bidston Observatory,

Birkenhead, Merseyside L43 7RA, UK

\section{Garret Hardin}

SIR - I must take umbrage at Robert Ubell's glib and prejudicial remarks con-

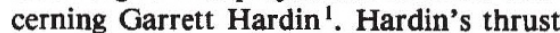
does not bespeak "racism" nor "chauvinism". Hardin's essential message is simply that our Earth is overpopulated and abused relative to available food and energy ${ }^{2}$. In his classic essay The Tragedy of the Commons (not mentioned by Ubell), Hardin incisively analysed our dilemma with overpopulation. And, lest we forget his message, remember our numbers are now approaching 6,000 million whereas we stood at a mere 3,000 million or so a little over a decade ago. Will the coming generations really want to survive to see 12,000 million? 24,000 million? I doubt it for, as Kingsley Davis argued ${ }^{3}$, our population is even now too large to retain our past gains in quality of life.

Department of Biology, L.H. WULLSTEIN University of Utah,

Salt Lake City, Utah 84112, USA

1. Ubell, R. Nature 305, 649 (1983).

2. Hardin, G. Diversity and Stability in Ecological Systems (Brookhaven Symp. Biol. No.22, 1969); Science 162, 1243; in Environment, Man and Survival (eds Wullstein, L.H. in Environment, Man and Survival (eds Wull

3. Davis, K. in Environment, Man and Survival (eds Wullstein, L.H. et al.) 15-34 (University of Utah Press, 1970).

\section{BeliketheGerman}

SIR - Regarding the continuing debate over nouns as adjectives, I have a simple proposal: English should follow the pattern used in German, where two or more words may be joined into a single word. This would resolve such conflicts as "base pair" versus "basepair", and the latter would become standard wordusage. The question of which word modifies which is resolved by the orderconvention that wordfragments nearer the wordbeginning modify those farther along. Among the systemadvantages for Naturearticlewriters would be journalarticlewordcountlimitproblemelimination, although optional parenthesesintroduction might facilitate clarityretention during, for example, this (( 60 -wordsentence)/(18-wordsentence)) reduction) process.

BiochemistryDepartment,

BirminghamAlabamaUniversity, Birmingham, Alabama 35294, USA

\section{Homology defined}

SIR - We in comparative biology are subjected to more arguments over the meaning of the term homology. $\mathrm{Mr}$ Moore's reply (Nature 22 September, p.268) to Mr Hughes (Nature 24 March, p.706), iterates the thesis that the homology observed on a broad scale in systematic and evolutionary study is somehow different or less refined than the fine level homology which can be studied in extant forms.

For fine similarities of extant taxa, $\mathrm{Mr}$ Moore develops the concept of "paramology". I find this proposition both cumbersome and naive. An unfortunate side effect of the sophistication of our scientific viewpoint is the propagation of jargon. If terms are introduced into the biological lexicon they should be metaphors for discrete phenomena or repeatable observations; not loosely constructed words with "derivatives". Shall we soon see in the ethnology literature an ethnology describing a shared behaviour? Or a sub or ultraparamology denoting lower and higher levels of paramology?

A second, more fundamental, difficulty stems from Mr Moore's concept of homology. In its general definition homology pertains to sameness of structure, independent of the evolutionary history of that structure. I agree that the sameness reflected in Mr Moore's example of the similarity between tetrapod arms and wings seems different from the exacting similarities seen in the biochemical fine structure of extant organisms, but whether this observation represents an ontological difference is not clear. Homology, in a broad sense, operates at several levels, and as better molecular biological techniques are developed, Mr Moore's paramologous structures will surely grade into homologies as discrete differences between paramologous structures are detected.

In practice homology is recognized on the basis of congruent distributions of attributes, and nonhomologous attributes are recognized by their noncongruence with this pattern. Amongst amniotes several clades are defined on the common presence of unique features. From this pattern we can recognize that a character, such as homeothermy, found in birds and mammals, is a nonhomology. Why? Because birds share more attributes with non-homeothermic crocodilians and lizards than they do with other homeotherms, that is, mammals. This indicates that the homeothermy of mammals and birds is not a general statement defining the level of the inclusive group of birds + crocodilians + lizards + mammals, hence this homeothermy represents two unique attributes rather than a homology.

The power of comparative anatomy in distinguishing patterns of homology is not new since it can be traced directly back to the pre-Darwinian typologists and perhaps even to Aristotle. This approach has resurfaced and been developed in recent years by practising systematists, somewhat independently, unfortunately, of other biologists. Admittedly eschewing a Hennigan view of the world, I wish to reiterate that homology is a comparative concept connoting sameness of structure, indicating group membership, and operating independently at several hierarchical levels - in the end Homology = Synapomorphy. Osborn Memorial Laboratory,

Yale University, New Haven,

Connecticut 06511, USA

\section{Numerology}

SIR - In the argument about numerology (Nature 7 July, p.11 and 1 September, p.8), both the numerologists and their critics miss the point. Being impressed by the near match of numbers does not make science, nor is it scientific simply to stress the remaining inaccuracy and complain of the lack of sense in the whole effort. This is a simple scientific problem: is there a phenomenon to be explained, or not?

This question can only be answered by making use of a statistical model which allows us to calculate accurately the probability of matching a number by a certain type of combination of specified numbers (such as 1 , e or $\pi$ ) with an accuracy as good as the one actually obtained. If this should turn out to be well below the usual critical limits of $5 \times 10^{-2}$ or $10^{-2}$, the numerological result has to be taken seriously and cannot be dismissed by any non-mathematical reasoning. In cases not totally evident no numerologist can expect scientific credibility without first establishing such statistical evidence. MARCUS GOSSLER Universitaetsbibliothek, A-8010 Graz, Austria 